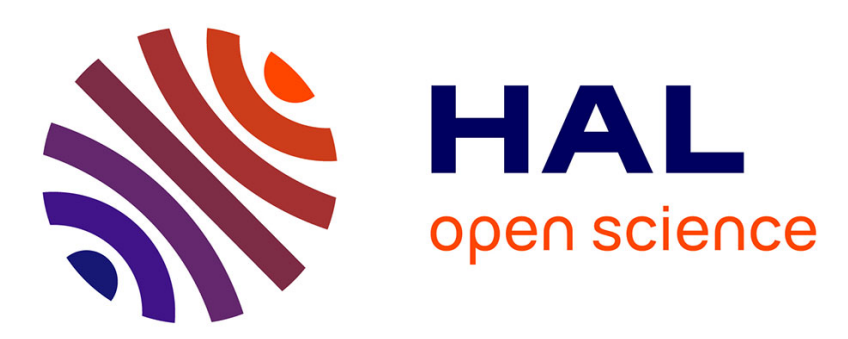

\title{
GRAIN BOUNDARIES IN HIGH TEMPERATURE DEFORMATION OF YTTRIA AND MAGNESIA CO-DOPED ALUMINA
}

\author{
S. Lartigue, C. Carry, L. Priester
}

\section{- To cite this version:}

S. Lartigue, C. Carry, L. Priester. GRAIN BOUNDARIES IN HIGH TEMPERATURE DEFORMATION OF YTTRIA AND MAGNESIA CO-DOPED ALUMINA. Journal de Physique Colloques, 1990, 51 (C1), pp.C1-985-C1-990. 10.1051/jphyscol:19901153 . jpa-00230066

\section{HAL Id: jpa-00230066 https://hal.science/jpa-00230066}

Submitted on 1 Jan 1990

HAL is a multi-disciplinary open access archive for the deposit and dissemination of scientific research documents, whether they are published or not. The documents may come from teaching and research institutions in France or abroad, or from public or private research centers.
L'archive ouverte pluridisciplinaire HAL, est destinée au dépôt et à la diffusion de documents scientifiques de niveau recherche, publiés ou non, émanant des établissements d'enseignement et de recherche français ou étrangers, des laboratoires publics ou privés. 


\title{
GRAIN BOUNDARIES IN HIGH TEMPERATURE DEFORMATION OF YTTRIA AND MAGNESIA CO-DOPED ALUMINA
}

\author{
S. LARTIGUE, C. CARRY* and L. PRIESTER \\ Laboratoire de Métallurgie Structurale, Bât. 413. Université Paris XI. \\ F-91405 orsay, France \\ * Laboratoire de Céramique, Ecole polytechnique Fédérale de Lausanne, 34 \\ Chemin de Bellerive, $\mathrm{CH}-1007$ Lausanne, Switzerland
}

\begin{abstract}
Résumé - La présence d'yltrium dans des alumines à grains fins dopées à la magnésie entraîne des modifications importantes des lois de comportement et de la microstructure de ces matériaux lors d'une déformation en compression à haute température. Les premiers résultats de l'étude en microscopie électronique révèlent une augmentation de la densité des dislocations à la fois dans les grains et dans les joints de grains. Ils mettent en évidence le rôle limitant de l'yttrium, fortement ségrégé aux joints, vis-â-vis des processus d'accommodation des dislocations intergranulaires; ces observations soni en bon accord avec la diminution de la vitesse de déformation obsenvée en présence d'yttrium.
\end{abstract}

\begin{abstract}
Abstracl - This is a first investigation on the role of yttrium in the ductility under high temperature deformation of fine-grained $\mathrm{Mg}$-doped aluminas. The changes in the constitutive laws of comoressive tests associated to the modifications of the microstructure are supported by the electron microscopy observations. The most important effect of yttria co-doping is an increase in the dislocation density both in the grains and in the grain boundaries; these observations reveal the hardening role of this element in the accommodation processes of grain boundary dislocations. This role of yttrium in grain boundary dislocation creep is in good agreement with the observed decrease in the deformation rate.
\end{abstract}

\section{I - INTRODUCTION}

Fine grained $\mathrm{Mg}$-doped aluminas display a high ductility behavior under high temperature deformation. The constitutive laws and the mechanisms are characteristic of a structural superplasticity in which grain boundary (GB) diffusion limited $\mathrm{GB}$ sliding is the predominant process $11-4 /$. A significant cavitation occurs as a non accommodation of GB sliding and grain growth takes place accounting for the observed decrease in the deformation rate. These processes involve different interface properties, such as their role as sources and sinks for vacancies and dislocations, that depend on GB crystallographic parameters and on the presence of segregated species.

Apart from a purely diffusional process, the superplasticity mechanisms can be understood by means of GB dislocation creep model, that can be summarized as follows $15,6 /$. The onset of a "pure" superplastic flow occurs with the creation and the motion of dislocations in the GB plane as a result of the shear stress. Different obstacles, triple points, ledges, subboundary junctions, induce a non uniformity of GB sliding and stress relaxations occur by emission of lattice dislocations. The absorption of these defects by other GB gives rise to a stimulation of $\mathrm{GB}$ sliding that is not only a deformation process but also a micromechanism of $\mathrm{GB}$ recovery 17/. Finally the displacement of steps associated with dislocations can be involved in GB migration $/ 5 /$.

Although GB dislocation creep is frequently evoked, there are little transmission electron microscopy (TEM) observations of linear defects in superplastically deformed materials. An important result of our previous work on $\mathrm{Mg}$-doped aluminas is the occurrence of non periodic dislocation networks in special near coincidence boundaries of the deformed samples that confirms the activity of GB dislocations during creep $18 /$. Furthermore, it is shown that special GB play a limiting role in the transmission of sliding and do not behave as good sources and sinks for lattice dislocations. Defects are rarely observed in general GB where arrommonation nrnroceps take nlane pacilv 
Thus the analysis of "special" GBS presentstwo main interests:

- Their contribution to the overall deformation must be taken into account, owing to their high proportion in fine grained aluminas $(\sim 30 \%) / 9 /$.

- They keep the memory of processes that occur in all the GBS of the polycristals.

All these phenomena can be affected by a change in chemical composition; it is well known that interg segregation can change the structure and/or the distribution of GBS in a polycrystal/10/; struclul chemistry are closely linked and both influence the GB properties $111 \%$. This paper reports the first vations, both macroscopic and microscopic, obtained on $\mathrm{Mg}$ doped aluminas co-doped with yttrium strongly segregates to the GB.

\section{II - EXPERIMENTAL}

Fine-grained alumina specimens, doped with a nominal concentration of $500 \mathrm{ppm} \mathrm{MgO}$ or $500 \mathrm{ppm}$ $500 \mathrm{ppm} \mathrm{Y}_{2} \mathrm{O}_{3}$ were obtained by hot pressing under a $45 \mathrm{MPa}$ pressure. Compressive creep experiment: performed under vacuum at $1500^{\circ} \mathrm{C}$ under $27,5 \mathrm{MPa}$ uniaxial pressure and at $1450^{\circ} \mathrm{C}$ under $20 \mathrm{MPa}$ : MPa pressures $12 \%$. Some hot pressed specimens have been submitted to the same treatment as the del ones but in stress free conditions allowing to assess microstructural differences between deforme annealed samples.

Grain boundaries have been analysed in hot pressed and deformed at $1500^{\circ} \mathrm{C}$ samples. Thin foils were ot by ian milling at $5 \mathrm{kVoperat}$ ing voltage and were observed in a $120 \mathrm{kV}$ Transmission Electron microscop macroscopic GB crystallographic parameters have been determined, allowing their classification as "s or "general" boundaries on the basis of a geometrical approach of three dimensional or one dimer coincidence models relevant to the rhombohedral symmetry and described in previous papers $/ 12,13 /$.

The GB distribution has been established by analysing GBS between two adjacent grains in different areas sample and has been compared with their theoretical distributions determined for a random distribut grain orientations $/ 14 /$.

\section{III - RESULTS AND DISCUSSION}

Yttrium co-doping gives rise to important modifications on the overall deformation behavior c doped aluminas:

- The deformation rate is strongly reduced (figure 1). At the beginning of the deformation, the slope curve $\ln |\dot{\varepsilon}|=f(\ln t)$ is not much different with or without yttrium. The presence of yttrium yield break which is more pronounced for samples recently obtained from purer powders /15/; in fact, been shown that this break occurs for a critical grain size $(d-2 \mu \mathrm{m})$, whatever the temperature thermomechanical treatment may be.

- An important observation is the strong increase in the activation energy estimated from the deforr rate values measured at the previous critical grain size $(d-2 \mu \mathrm{m})$. This energy, ranging betwee and $800 \mathrm{~kJ} /$ mole, is higher than the value of $400 \mathrm{~kJ} / \mathrm{mole}$ obtained for $\mathrm{Mg}$-doped aluminas corresponds to a deformation mechanism controlled by aluminium GB diffusion $/ 1$.

However, the stress exponent in the $\dot{\varepsilon} \sim \sigma^{n}$ relationship is not markedly affected by yttrium and values $r \varepsilon$ between 1 and 2 are observed. But the results of $n$ measurements by stress jumps during a creep test that $n$ decreases slightly (from 1,8 to 1,3 ) $/ 16 /$ as the grain size increases up to the critical grair $(2 \mu \mathrm{m})$ and remains constant for higher grain sizes in yttria-doped alumina.

The microstructural features are also strongly modified by yttrium co-doping:

- Significant grain elongation is observed (figure 2) for samples deformed up to the break in strait curves (figure 1).

- The cavitation measured at equivalent strain levels is strongly decreased.

- The basal texture measured at the same strain level is not much increased.

- The grain growth rate stress enhancing effect is less pronounced. 

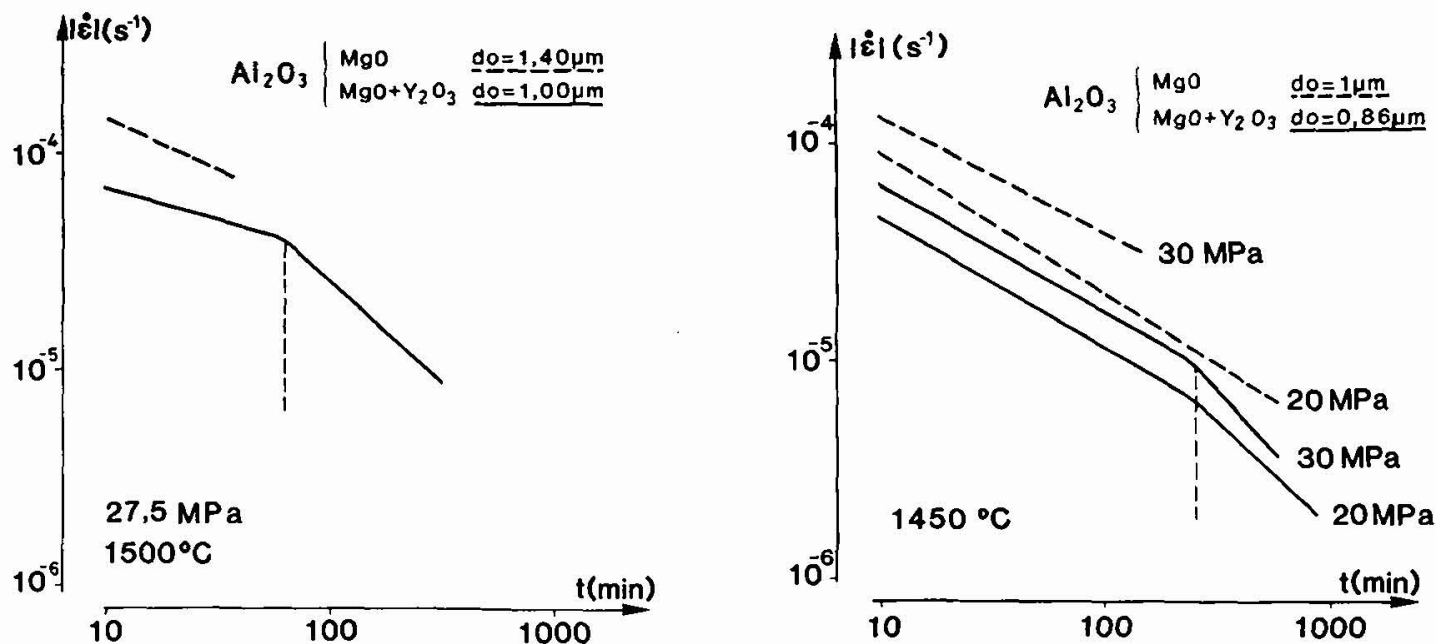

Fig.1. - Strain rates versus time in creep conditions (constant stress). For yttria doped materials a break in the slope is observed for a critical grain size $(d-2 \mu \mathrm{m})$.

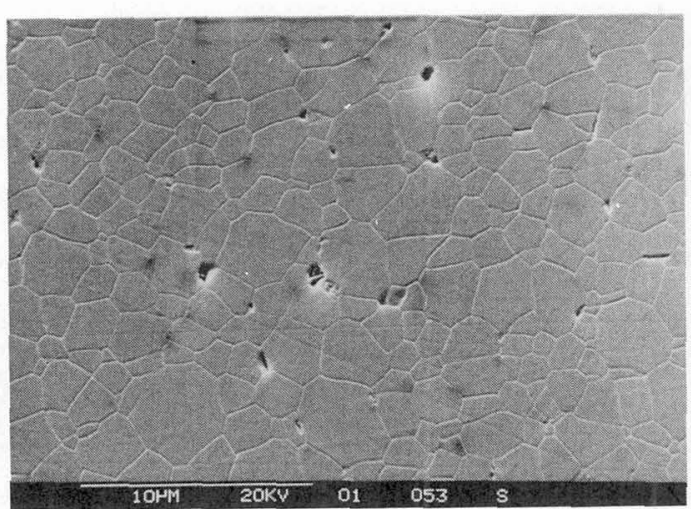

Mg-doped $\mathrm{Al}_{2} \mathrm{O}_{3} \quad \sigma=-27,5 \mathrm{MPa}$
$1500{ }^{\circ} \mathrm{C}, 38$ minutes, $\varepsilon=-0,26$

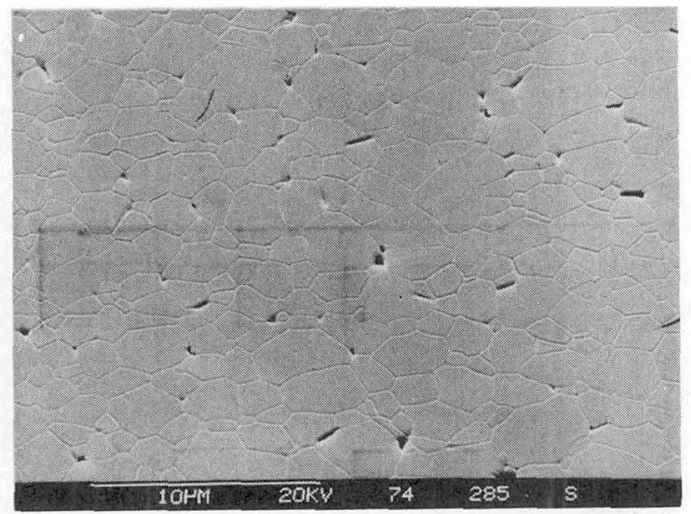

$\mathrm{MgO}+\mathrm{Y}_{2} \mathrm{O}_{3}$-doped $\mathrm{Al}_{2} \mathrm{O}_{3} \quad \sigma=-27,5 \mathrm{MPa}$ $1500{ }^{\circ} \mathrm{C}, 77$ minutes, $\varepsilon=-0,27$

Fig. 2. - Grain aspects in deformed samples. The uniaxial stress is perpendicular to the large side of micrographs. 
A careful interpretation of these macroscopic results requires detailed analyses of the influence of yttri the microstructure including intragranular features as well as GB distributions and characteristics observations were performed on yttria doped samples which have been deformed up to a time correspont the break in the deformation curve (figure 1).

- The proportion of "special" GBS is not significantly modified by yttrium co-doping.

- The main difference is the occurrence of basal twins and planar stacking faults, both crossing the grains of the microstructure, that probably result from a growth accident (figure 3 ). The fault $\mathrm{pl}$ most often parallel to the $\{11 \overline{2} 0\}$ plane and the displacement vectors determined by image compI are rather small $R \sim \frac{1}{12}[0001]$ or $R \sim \frac{1}{12}[10 \overline{1} 1] / 17 /$.

- As in Mg-doped samples, the GB planes are neither dense nor symmetrical, in agreement witl usual curved profile.

The most important observations are the increase in the density of intragranular linear defects ar occurrence of non periodic nelworks of dislocations in "special" and "general" GB, both in hot presse deformed yttria co-doped samples (figure 4). It is noteworthy that a general GB containing dislocati always connected to a special GB that presents periodic or non periodic dislocation arrays. Occasional. dislocation features suggest that these defects have been emitted by sources in the GB (figure 5).

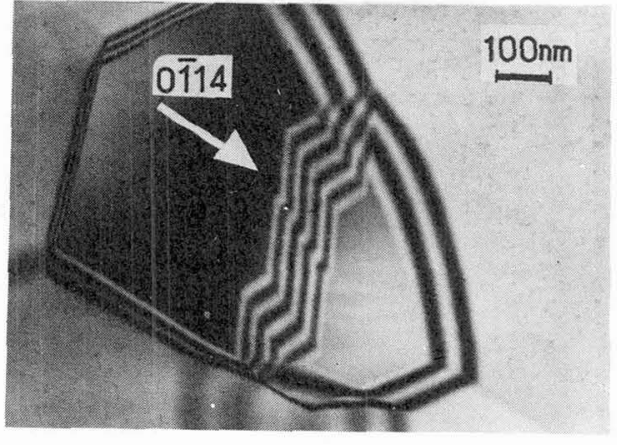

Fig. 3-Brightfield TEM image of a planar stacking fault. The two fault planes present different displacement vectors $\frac{1}{12}[10 \overline{1} 1]$ and $\frac{1}{12}$ [0001].

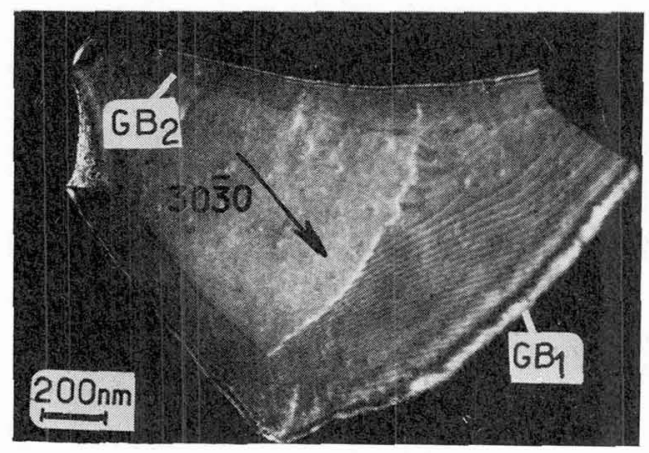

Fig. 5 - Dark field TEM image of two GB containing dislocations with a curved profile. $\mathrm{GB1}$ is a "general" GB. GB2 is a "one dimensional" coincidence GB (matching planes (1123)) /13/.

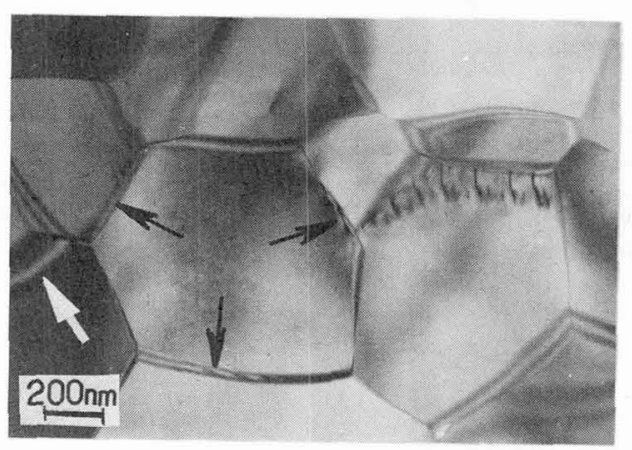

Fig. 4 - Bright field TEM image of periodic and periodic dislocation network (arrowed). Lattice locations are present along a grain boundary.

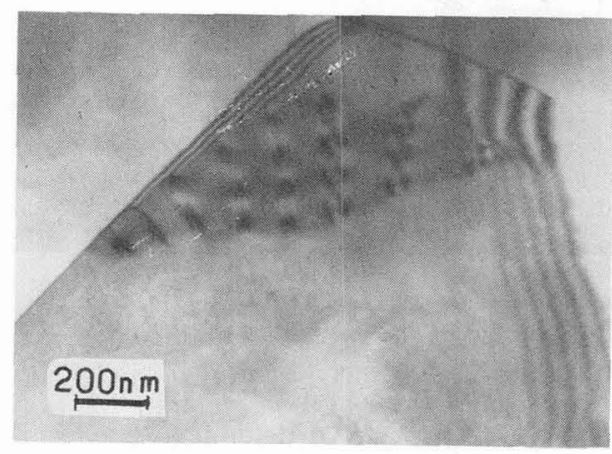

Fig. 6 - Bright field TEM image of lattice disloca which interact with a "special" GB. 


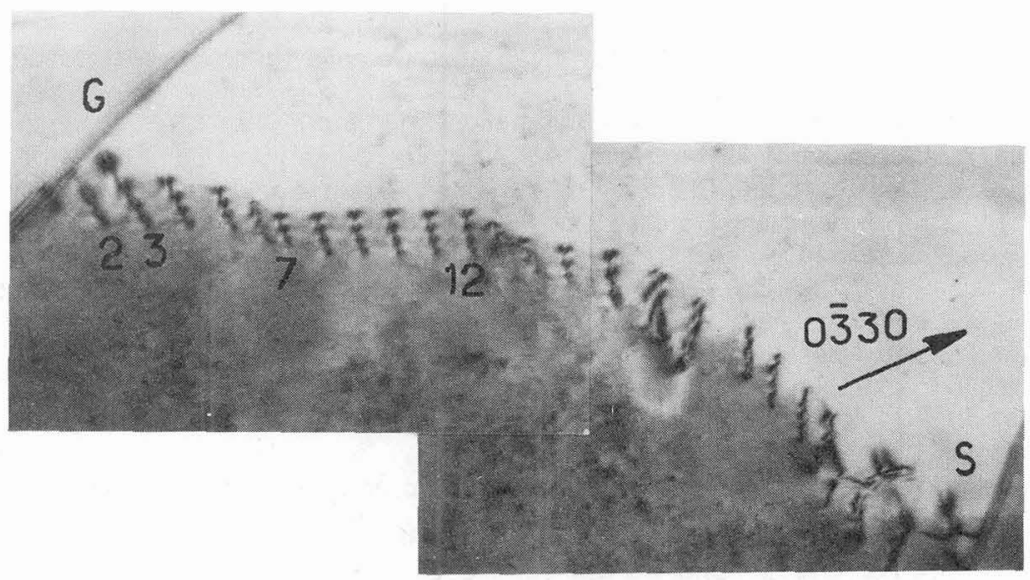

Fig. 7 - Bright field TEM image of a lattice dislocation array. The basal dislocations 2 and 3 and 71012 are contained in two different planes that are not the basal slip plane (0001). Some dislocation nodes are observed near the "special" GB S.

Intragranular dislocations are more numerous in the deformed sample (figures 6 and 7). They must have been emitted by $\mathrm{GB}$ as the flow stress required to activate sources within grains is too high $/ 4 /$. For example, in the figure 7 , the dislocations probably originate from the "general" boundary $G$, and interact with the "special" boundary $S$, the dislocations numbered 2 to 12 are of basal type, but they are not contained in a slip plane, involving climb processes.

The microstructural observations emphasize that accommodation of GB sliding occurs by stress relaxations in the grains, in agreement with the development of a basal texture and a grain elongation. They suggest a hardening role of yttrium in the dynamic recovery of GB structure that results from absorption of dislocations. Such an impediment of accommodation processes most probably arises from a strong segregation of yttrium that have been detected by STEM. The hypothesis of a decrease in the intergranular diffusion coefficient by segregation could explain the lower dislocation mobility $/ 18,19$ / and play a role in the reduction of the deformation rate in comparison with this rate for the $\mathrm{Mg}$-doped specimens; it is supported by a high value of the activation energy measured for increasing grain size during the deformation.

\section{IV - CONCLUDING REMARKS}

Both macroscopic and microscopic results are consistent with a hardening role of yttrium in the absorption of lattice dislocations by grain boundaries. Reduction of the dislocation mobility induces a decrease on the deformation rate, and stress concentrations built up at grain boundaries are relaxed by emission of lattice dislocations.

TEM observations have been made on samples deformed up to the break in the deformation rate curve; this break probably corresponds to the end of a transient state in so far as no variations in the stress exponent and in the activation energy are noticed after it. The critical grain size associated to the break could to be linked to a critical solute concentration at the grain boundary. To belter understand these phenomena, new experiments are now in progress. STEM analyses of GB in relation with GB crystallographic parameters and creep test experiments on materials with higher yttrium concentration (up to $1500 \mathrm{ppm} \mathrm{Y}_{2} \mathrm{O}_{3}$ ) and obtained from purer powders with lower impurity contents.

\section{Acknowledgements}

This work has been supported in part by the Swiss National Science Foundation. 


\section{REFERENCES}

/1/ Fridez, J.D., Carry, C. and Mocellin, A., Advances in Ceramic 10, ed. by W.D. Kindery, Amer. Cl Soc., Columbus, OH (1984) p. 720.

121 Carry, C. and Mocellin, A., Ceramics International 13 (1987) 89.

/ 3 / Cannon, R.M., Rhodes, W.H. and Hever, A.H., J. Amer. Ceram. Soc. $63(1980) 46$.

$14 /$ Heuer, A.H., Tighe, J.N. and Cannon, R.M., J. Amer. Ceram. Soc. 63 (1980) 53.

$15 /$ Pond, R.C., Smith, D.A. and Southerdern, P.W.J., Philos. Mag. A 37 (1978) 27.

/6 / Valiev, R.Z., Gertsman, V. and Kaibyshev, O.A., Phys. Stat. Sol. (a) 97 (1986) 11.

171 Valiev, R.Z., Kaibyshev, O.A., Sergeev, V.I. and Zelin, MG., Res. Mec. 12 (1984) 219.

$18 /$ Lartigue, S. and Priester, L., J. Amer. Ceram. Soc. 71 (1988) 430.

$19 /$ Lartigue, S. and Priester, L., J. Phys. C5.49 (1988) 451.

$110 /$ Bouchet, D., and Priester, L., Scripta Metall. 21 (1987) 475.

$111 /$ Priester, L., Rev. de Phys. Appl. 24 (1989) 419.

$112 /$ Grimmer, H., Helv. Phys. Acta 62 (1989) 231.

/13/ Grimmer, H., Bonnet, R., Lartigue, S. and Priester, L., to be published in Philos. Mag.

/14/ Lartigue, S., Doctoral Thesis, Orsay (1988).

$115 /$ Carry, C. and Gruffel, P., to be published.

/16/ Carry, C. and Mocellin, A., Proc. of Brit. Ceram. Soc. 33 (1983) 101.

$117 /$ Lartigue, S. and Bonnet, R., this session.

$118 /$ Lartigue, S. and Priester, L., Acta Metall. 31 (1983) 1809.

$/ 19 /$ Swiatnicki, W.A. and Grabski, M.W., Res. Mec. 12 (1984) 219. 